\title{
RAMAN SPECTROSCOPY OF SHOCKED WATER
}

N. C. Holmes, W. J. Nellis, W. B. Graham Lawrence Livermore National Laboratory Livermore, CA 94550

and

G. E. Walrafen

Howard University

Washington, D.C. 20059

This paper was prepared for submittal to Proceedings of the APS Topical Conference on Shock Waves in Condensed Matter - 1985 Spokane, WA July 22-26, 1985

August, 1985

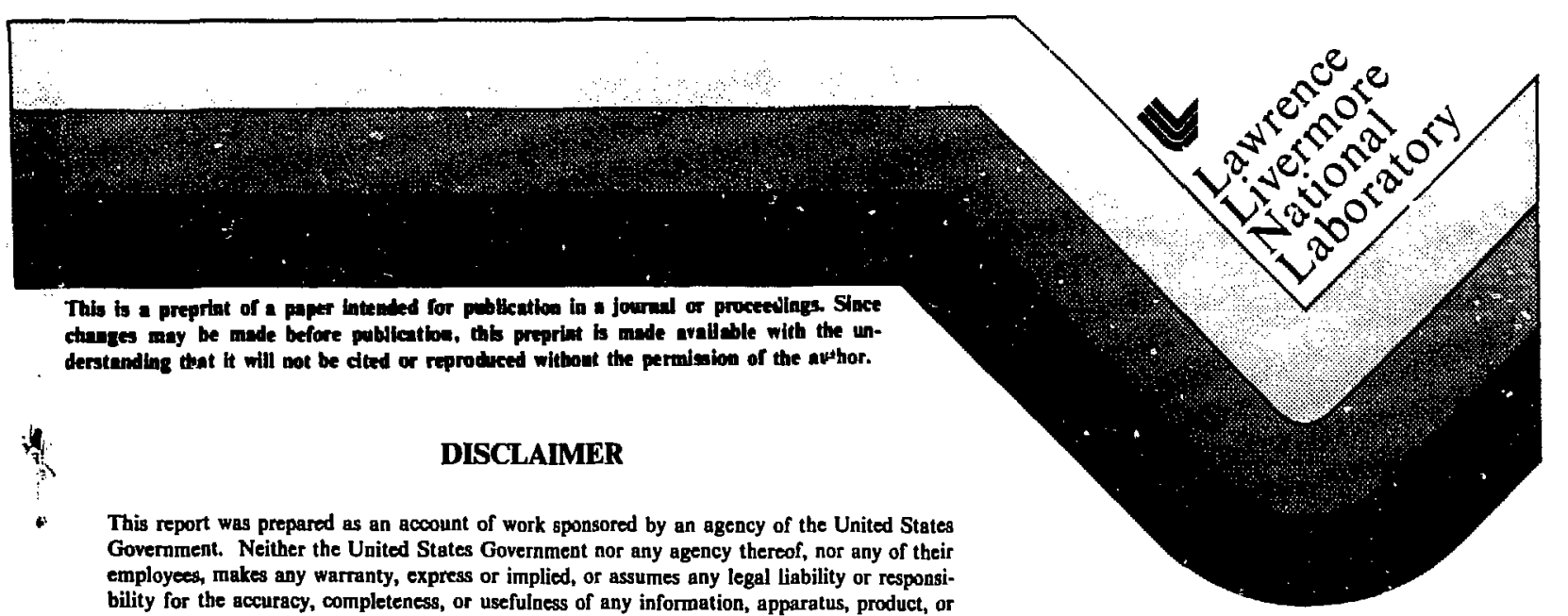
process disclosed, or represents that its use would not infringe privately owned rights, Reference herein to any specific commercial product, process, or service by trade name, trademark, manufacturer, or otherwise does aot necessarily constitute or imply its endorsement, recommendation, or favoring hy the United States Government or any agency thereor. The views and opinions of authors expressed herein do not necessarily state or reflect those of the United States Government or any agency thet:of. 
and

G. E. Walrafen

Howard University

Washington, D.C. 20059

\section{ABSTRACT}

We describe a new technique for recording spontaneous Raman spectra from molecules during the passage of strong shock waves. We have used this technique to study the OH-stretch band of liquid $\mathrm{B}_{2} \mathrm{O}$ shocked to pressures uo to $26 \mathrm{GPa}$ and $1700 \mathrm{~K}$. The shape of the band changes over the range 7.5-26 GPa, and is described wall by a two-component mixture model, implying changes in the intermolecular coupling of shock compressed water molecules. We iscuss the implications of the spectra on the mechanism responsible for the electrical conductivity of shocked $\mathrm{H}_{2} \mathrm{O}$.

\section{INTRODUCTION}

The passage of strong shock waves through molecular systems allows the study of these systems under extremes of pressure, density, and temperature. Most shock experiments measure bulk properties of molecules such as equation-of-state, conductivity, temperature, sound velocity, and so forth. These results for water are contained in Ref. 1 and references therein. However, our knowledge of the detalls on a molecular level in shock-compressed matter is most rudimeritary. We generally do not know the molecular chemistry responsible for the bulk behavior of shocked substances. A detailed understanding requires a knowledge of the chemical species existing behind the shock front, what reactions occur, and the reaction kinetics, all of which may be functions of both time and position. During the past few years, modern spectroscopic techniques have just begun to be applied to this new and important regime of chemical physics.

For example, consider the case of water. Between 3 and $30 \mathrm{GPa}$ (30-300 kbar) the electrical conductivity of shocked $\mathrm{B}_{2} \mathrm{O}$ increases by over five orders of magnitude, 1-3 saturating at a value of about 20 $(\Omega-\mathrm{cm})^{-1}$ above $30 \mathrm{GPa} .1$ Hamann and $L$ inton 4 proposed that water becomes fully ionized to $\mathrm{H}_{3} \mathrm{O}^{+}$and $\mathrm{OH}^{-}$at $15-20 \mathrm{GPa}$ and that transport of these lons could account for the observations. This is the same process which occurs in water at ambient conditions, but greatiy 
enhanced by the high temperature and density behind the shock front. The extensive studies of water ices at high pressure cast little light on this question, for the phase is different (shocked water is liquid above about $5 \mathrm{GPa}$ ). and the temperatures of $2000 \mathrm{~K}$ and higher far exceed what is currently possible in static compression experiments. What is clearly needed is a method to probe directly for the existence of new molecular species behind a strong shock wave front. It is precisely this problem which has motivated this work.

\section{RAMAN SPECTROSCOPY}

Raman spectroscopy is often applied to the study of molecular systems. The Raman effect is a type of inelastic light scattering in which a fraction of the energy of a phoion incident on a molecule is exchanged with a molecular vibrational mode. When the process results in lower frequency (red-shifted) scattered light it is termed stokes scattering; scattered light of higher frequency is called anti-stokes scattering. The frequency shifts of the scattered light allow the determination of the molecules present, their structure, and often provide insight into the local environment of the scattering molecules. A great number of techniques have been developed which exploit this effect, and they have recently been summarized by schmidt. 5 By far the most commonly used technique is spontaneous Raman scattering, a process for which the scattered intensity is linearly related to the incident light intensity. Spontaneous anti-stokes Raman scattering has been used to determine the temperature of shocked liquids. 6 A variety of non-linear spectroscopic methods are now in use, which feature intense laser sources to produce stimulated scattering. Recently, stimulated Raman back-scattering has been used to measure the shift in the $v_{1}$ vibrational mode of benzene shocked to $1.2 \mathrm{GPa} .^{7}$

In the work reported here on shocked $\mathrm{H}_{2} \mathrm{O}$, we chose to use spontaneous Stokes Raman scattering to observe the ok-stretch vibrational mode for a variety of reasons. The bandwidth of this technique is large and limited only by the spectrograph, ideal for observing the oH-stretch for which the width of the frequency spectrum is typically $1000 \mathrm{~cm}^{-1}$. spontaneous Raman scattering occurs into $4 \pi$ steradians, simplifying experiemental design. It does not require phase-matching at critical angles, an important advantage when dealing with large and moving refractive index gradients at the shook front. Most importantly, alnost all previous Raman spectroscopic studies of water in liquid and ice phases have employed spontaneous scattering, so our results can be easily compared to the literature. Also, the molecular ions expected in shocked water should be distinguishable from the scattering from water molecules. The disadvantage of the spontaneous method is the weakness of the scattered light. Typlcal scattering cross-gections are of the order $10^{-29} \mathrm{~cm}^{2}$ and lead to total scattering fractions of $10^{-7}$ or less. This makes detection difficult. Often epontaneous Raman spectra are obtained in minutes to hours while a line or band is carefully scanned. This is impractical in a shock wave experiment which lasts for about $10^{-6}$ seconds, precluding both signal averaging and scanning techniques. Recent advances in optical detector technology, described below, now make it possible to record braodband spectra in a much briefer Interval.

\section{EXPERTMENTAL DESCRIPTION}

The experimental arrangement is shown schematically in Figure 1. strong shosk waves were generated by planar impactors accelerated to high 
velocities by a two-stage light-gas gun. 8 The water specimens were triply-distilled and deionized and were initially at $20 \mathrm{C}$ and atmospheric pressure. The specimen holders were Eabricated of 1100 aluminum and the baseplates of the holder's were diamond-machined to minimize scatter of laser light into the detection optics. The dimensions of the target and impactor were chosen to provide a large volume of uniformly shocked water free of attenuation and edge effects.

An unpolarized $\mathrm{KrF}$ laser (248 $\mathrm{nm}, 0.2 \mathrm{~J}, 10 \mathrm{~ns}$ (FWH( pulsewidth) was used to excite the Raman spectrum. The use of an ultraviolet laser exploits the fourth-power frequency dependence of the scattering cross-gection to maximize the signal. The lasez bean was aligned colinear with the centerline axes of the target and impactor. A Eused silica len: was used to slightly focus the laser into the target, but the intensity was kept well below the threshold for stimulated scattering. The laser beam entered the water sample through an electronic-grade, $z$-cut, $\alpha$-quartz window which displayed no detectable fluorescence on laser illumination. Raman scattered light was collected at 45 degrees to this axis by an $f / 4$ fused silica lens and a matched lens formed an image on the input slit of the spectrograph of a small region 3.5 mu behind the shock front at roughly $1: 1$ magnification. Trigger pins installed in the water sample provided tining signals for the laser and detector

electronics. A flat-field $0.3 \mathrm{~m}$ focal length spectrograph dispersed the

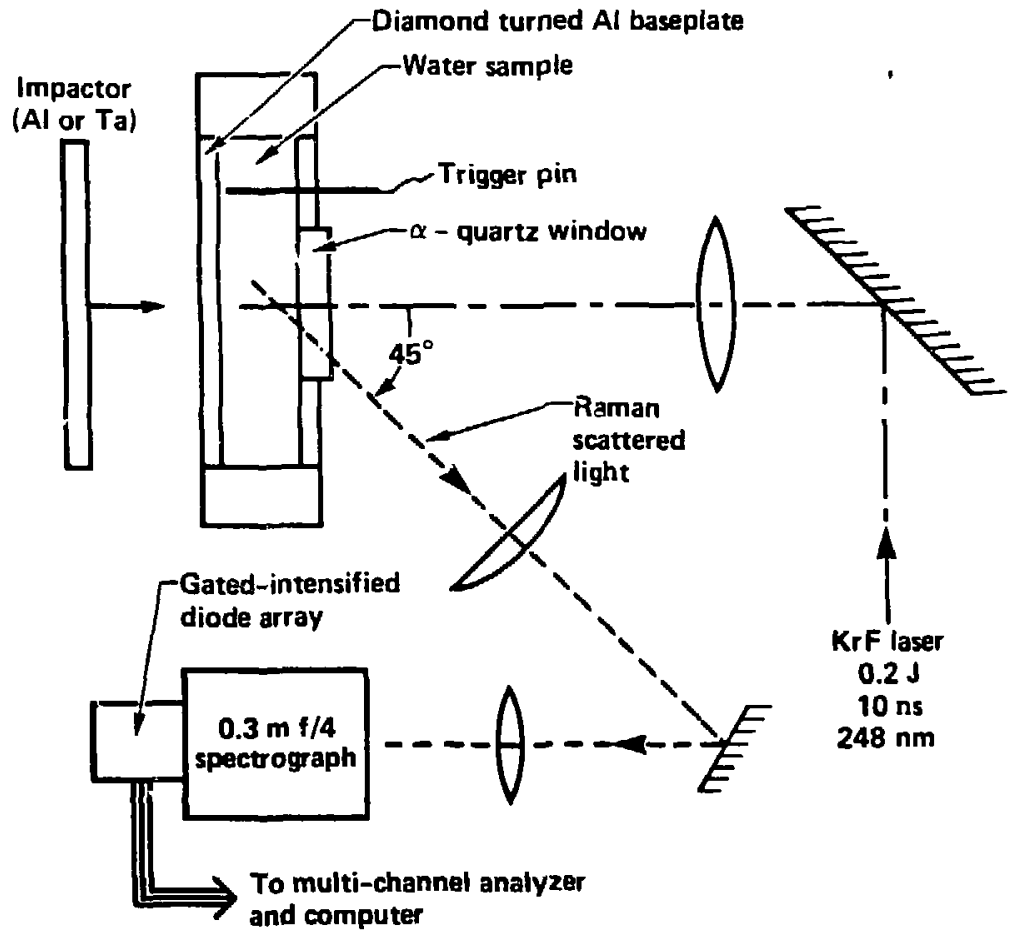

Eig. 1. The experimental arrangement for spontaneous Raman spectroscopy of shocked water. A two-stage light-gas gun is used to accelerate the impactor, generating strong shock waves in liquid water samples. The spectrograph and detector are located outside the target vacuum chamber. 
scattered light for detection by a gated and intensified 1024-element linear diode array detector. The intensifier was required since the maximum amount of scattered light entering the spectrograph was about $10^{-10} \mathrm{~J}$. The intensifier was gated on for $50 \mathrm{~ns}$, allowing adequate discrimination against thermal emission from the hot, shocked water. The diode signals were digitized by a multichannel analyzer and stored in a small desk-top computer for analysis. Spectral resolution was measured to be about $15-20 \mathrm{~cm}^{-1}$, limited mainly by the bandwidth of the $\mathrm{krF}$ laser.

The experimental parameters for five experiments are listed in Table I. Pressures and densities were calculated using the impactor velocity, 9 the known equations-of-state of the 1mpactor materials (Al, Ta),10 the baseplate,10 the water sample,1,11 and the use of the impedance-matching method.12 shock temperatures were calculated using a constant $C_{v}$ model.13 In all cases the shocked water samples were in the liquid state based on the melting curve for ice VII. 14

Table I. Experimental conditions for five spontaneous Raman experiments in shocked $\mathrm{B}_{2} \mathrm{O}$. The impactor material was aluminum for shots 8 and 9 , tantalum for the others. Shock pressures and densities were calculated on the basis of known equations-of-state using the impedance-matching method. The shock temperatures were calculated using a constant $C_{v}$ model.13

\begin{tabular}{lcccc}
\hline Shot & $\begin{array}{c}\text { Projectile } \\
\text { Velocity } \\
(\mathrm{km} / \mathrm{s})\end{array}$ & $\begin{array}{c}\text { Pressure } \\
(\mathrm{GPa})\end{array}$ & $\begin{array}{c}\text { Density } \\
\left(\mathrm{g} / \mathrm{cm}^{3}\right)\end{array}$ & $\begin{array}{c}\text { Calculated } \\
\text { Temperature } \\
(\mathrm{K})\end{array}$ \\
\hline Raman 8 & 2.1 & 7.5 & 1.56 & 640 \\
Raman 9 & 2.88 & 11.7 & 1.71 & 840 \\
Raman 11 & 2.90 & 21.9 & 1.94 & 1480 \\
Raman 12 & 2.86 & 21.4 & 1.93 & 1460 \\
Raman 13 & 3.23 & 25.7 & 2.00 & 1710 \\
\hline
\end{tabular}

\section{RESULTS AND DISCOSSION}

The OH-stretch spectrum of $\mathrm{H}_{2} \mathrm{O}$ shocked to $7.5 \mathrm{GPa}(75 \mathrm{kbar})$ and $640 \mathrm{~K}$ is compared with water at ambient conditions in $\mathrm{Fig.} \mathrm{2.} \mathrm{The} \mathrm{band}$ shape is strongly asymmetric in the shocked case, and the double-peak structure is no longer evident. More striking is the comparison with indner's data for statically compressed water at $0.4 \mathrm{GPa}$ and $670 \mathrm{k}^{15}$ shown in Flg. 3. The effect of increased density alone is evident in the much more pronounced scattering in the low frequency range bolow 3400 $\mathrm{cm}^{-1}$. As the shock pressure is increased to $22 \mathrm{GPa}$ (Fig. 4) and 25.7 GPa (Fig. 5) the band gradually becomes more symmetric and the scattering intensity decreases substantially. 


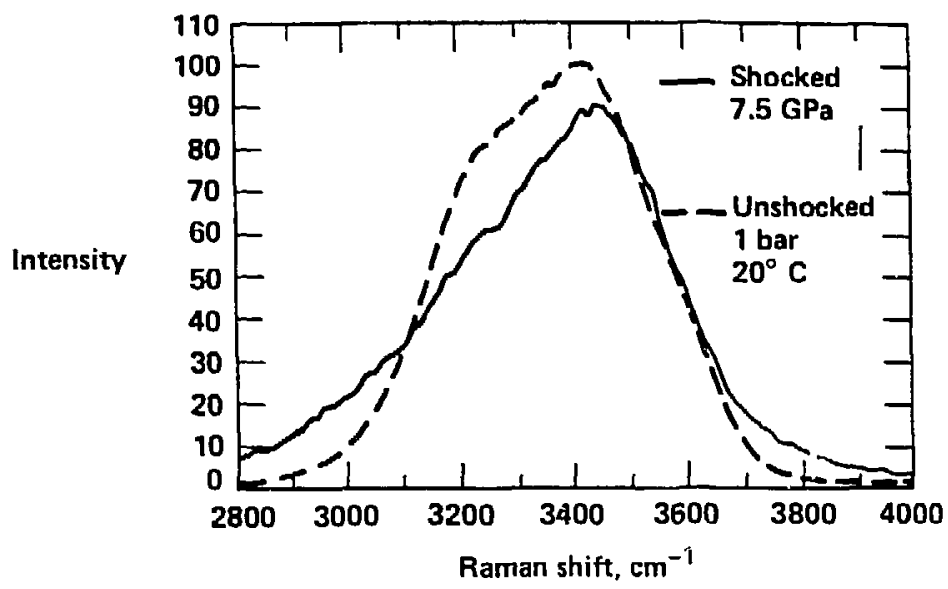

Fig. 2. Spontaneous Raman spectra of the oH-stretch band of liquid water at ambient conditions (dashed curve) and at $7.5 \mathrm{GPa}$ and $640 \mathrm{~K}$ (solid curve).

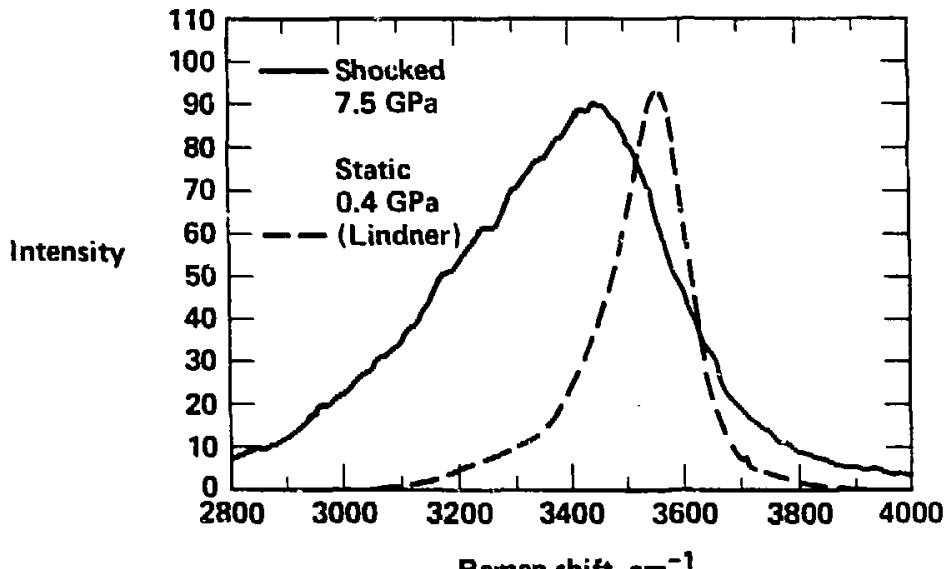

Raman shift, $\mathrm{cm}^{-1}$

Fig. 3. A comparison of of-stretch Raman spectra at nearly the same temperatures but at different pressures. The dashed curve is static data from Lindner ${ }^{15}$ at $0.4 \mathrm{GPa}$ and $670 \mathrm{R}$. The solid curve is the spectrum of shocked $\mathrm{B}_{2} \mathrm{O}$ at $7.5 \mathrm{GPa}$ and $640 \mathrm{~K}$. 


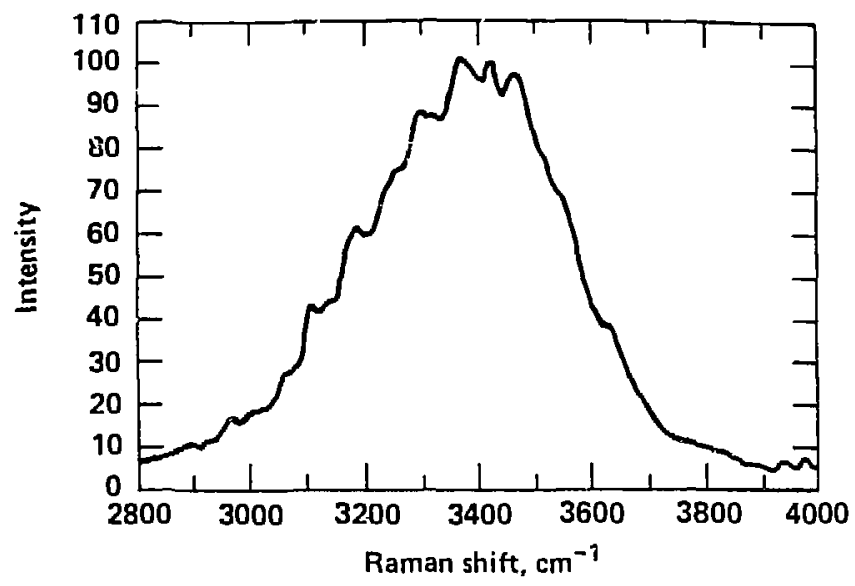

Fig. 4. Spontaneous Raman spectrum of shocked $\mathrm{H}_{2} \mathrm{O}$ at $22 \mathrm{GPa}$ and $1480 \mathrm{~K}$.

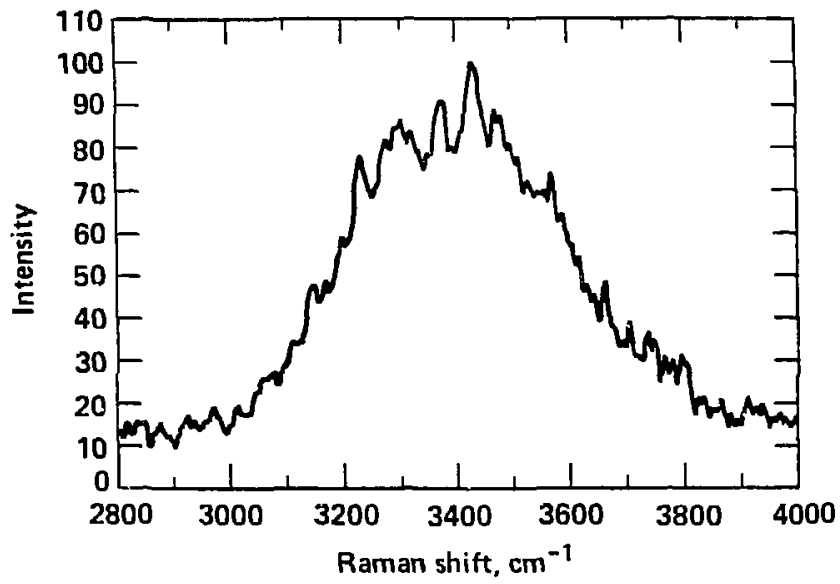

Fig. 5. Spontaneous Raman spectrum of shocked $\mathrm{H}_{2} \mathrm{O}$ at $26 \mathrm{GPa}$ and $1700 \mathrm{~K}$.

The changes in the shape of the ot-stretch band can be described by a two-component mixture model for shocked water. That is, the bandshape is thought to arise from the superposition of scattering from two spectroscopically distinguishable classes of water molecules. One class of molecules is strongly hydrogen-bonded to its nearest neighbors in small tetrahedral clusters of the type shown in Figure 6 . The strong intermolecular coupling results in a reduction of the of-stretch frequency compared with isolated molecules in the liquid. The second class of molecules is thought to be elther weakly bondeal6 or essentially monomeric water.17 These molecules have a slightly higher Of-stretching frequency. This model is based on the observation of over.lapping components in the Raman spectrum of liquid water at or near ambient conditions.16,17 studies of ice VII indicate an inverse correlation between the $0-0$ distance and intermolecular $0-H$ distance. 18 Under compression, as the $0-0$ distance decreases, the OH-stretch frequency decreases reflecting the weakening of the longer $\mathrm{O}-\mathrm{H}$ bonds. 


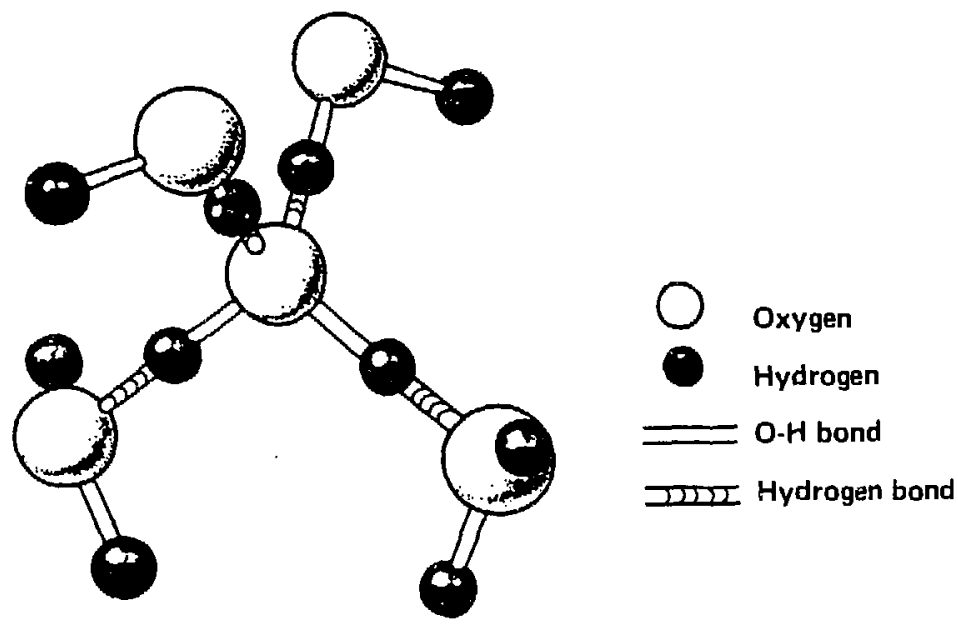

Fig. 6. The hydrogen-bonded structure of liquid water.

We used a least-squares technique ${ }^{19}$ in an attempt to fit the data by a sum of two Gaussian components. The use of Gaussians seemed reasonable based on the observation that the wings of the band were of Gaussian shape for all cases, and because the broadening mechanisms expected behind the shock front lead to inhomogeneous broadening. A two-component fit is found to agree very well with all of the spectra of shocked $\mathrm{B}_{2} \mathrm{O}$, leading to $\mathrm{rms}$ errors of about 28 ; the residual errors appear to be random in nature. The results of the fits are summarized below in Table II. We note that the positions of the components both show a gradual decrease in frequency with increasing pressure as expected.

Table II. Results of two-component Gaussian decompositions for OH-stretch spectra of shocked $\mathrm{B}_{2} \mathrm{O}$. Refer to Table I for physical conditions. I refer to the peak height of each component relative to a value of 1.0 at the maximum of the measured spertrum. The values of $v$ and $\Delta v$ are in $\mathrm{cm}^{-1}$ and refer to the center frequency and width (FWHM) of each component in the spectral decomposition.

\begin{tabular}{|c|c|c|c|c|c|c|c|}
\hline \multicolumn{3}{|c|}{ Component 1} & \multicolumn{3}{|c|}{ Component 2} & \multicolumn{2}{|c|}{ rms } \\
\hline I & $\Delta v$ & $v$ & $\mathbf{I}$ & $\Delta v$ & $v$ & fit er & ror \\
\hline .62 & 490 & 3345 & .43 & 208 & 3479 & 1.1 & 8 \\
\hline $\begin{array}{l}.68 \\
.49\end{array}$ & $\begin{array}{l}466 \\
353\end{array}$ & $\begin{array}{l}3358 \\
3260\end{array}$ & $\begin{array}{r}.33 \\
.66\end{array}$ & $\begin{array}{l}208 \\
300\end{array}$ & $\begin{array}{l}3461 \\
3462\end{array}$ & $\begin{array}{l}1.2 \\
2.1\end{array}$ & $\begin{array}{l}8 \\
8\end{array}$ \\
\hline $\begin{array}{r}.36 \\
.14\end{array}$ & $\begin{array}{l}240 \\
166\end{array}$ & $\begin{array}{l}3185 \\
3241\end{array}$ & $\begin{array}{r}.84 \\
.72\end{array}$ & $\begin{array}{l}325 \\
415\end{array}$ & $\begin{array}{l}3423 \\
3426\end{array}$ & $\begin{array}{l}1.8 \\
3.7\end{array}$ & $\begin{array}{l}8 \\
8\end{array}$ \\
\hline
\end{tabular}


The total amount of scattered light in the two components changes markedly over the pressure range. The dependence of the lower-frequency, hydrogen-bonded component is plotted vs. pressure in Figure 7 . We see from the figure that the hydrogen-bonded water structure dominates for pressures up to about $12 \mathrm{GPa}$, and then gradually decreases in intensity, diminishing to zero at about $26 \mathrm{GPa}$. On this basis, we claim that the spectra imply a destruction of hydrogen-bonded molecular complexes at very high shock pressures.

\section{CONDUCTIVITY OF SHOCKED WATER}

Contributions to the Raman spectrum from $\mathrm{H}_{3} \mathrm{O}^{+}$should be distinguishable from the OH-stretch water band. The oH-stretch frequency of $\mathrm{B}_{3} \mathrm{O}^{+}$has been measured to be between $2900-3000 \mathrm{~cm}^{-1}$ by both Raman 20 and infrared 21 techniques in solutions of strong acids. No such band is distinguishable in our data. This is perhaps not surprising. The conductivity in liquid water is believed to involve the transfer of electric charge through hydrogen-bonded molecular complexes of the form $\mathrm{H}_{9} \mathrm{O}_{4}{ }^{+}$and $\mathrm{H}_{7} \mathrm{O}_{4}{ }^{-} .22$ when the hydrogen-bonded complexes are broken at high shock pressures, this process is not likely to contribute significantly to the electrical conductivity. If large concentrations of the $\mathrm{B}_{3} \mathrm{O}^{+}$ions were present, whether hydrated or not, they should be discernable in the spectra. An alternative hypothesis is that conduction occurs by the transport of essentially free $\mathrm{H}^{+}$and $\mathrm{OH}^{-}$lons. The proton cannot be observed in our experiments, but the hydroxyl ion should be discelnable unless its vibrational frequency is pressure shifted to overlap the oH-stretch band of water. It is also possible that the character of the $O H$ bond becomes more ionic at high shock pressures in a way similar to that proposed for symmetric ice VII.18 since the or ions cannot be distinguished in our spectra, further experiments are required to resolve this uncertainty.

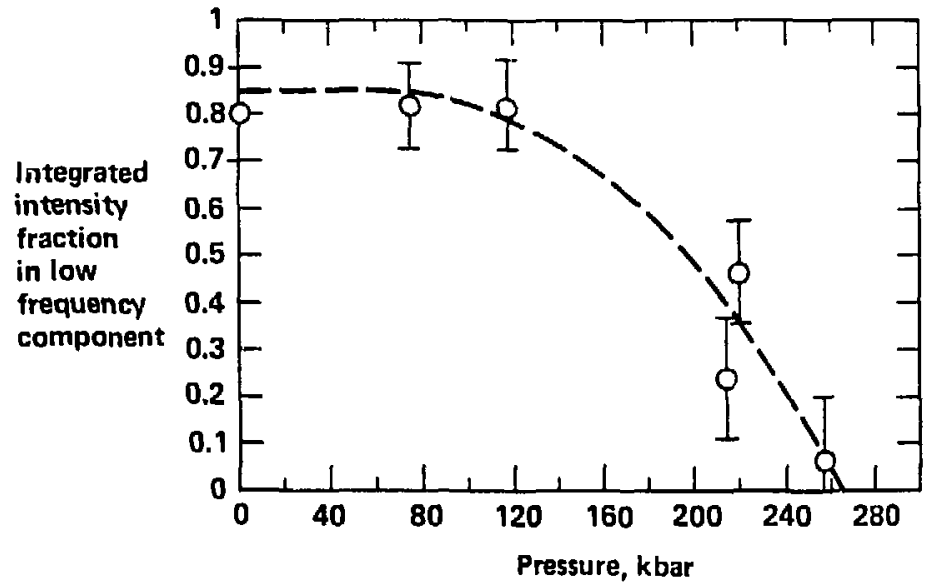

Fig. 7. Total scattering in the low-frequency component of the mixture model plotted vs. pressure. The decrease in the strength of this component indicates the gradual destruction of hydrogen bonds with increasing shock pressure and temperature. 
We have observed the behavior of the ot-stretch band of licuid water to $26 \mathrm{GPa}$ shock pressure and $1700 \mathrm{~K}$ by spontaneous Raman scattering behind the shock front. The technique we have described can record spontaneous Raman spectra in a single shot from shocked samples, and the method can be used up to the transparency limit of the material under study. The spectra we obtained show that the of vibration persists up to the highest pressures studied. All of the shocked water spectra are consistent with a two-component mixture model, where the components are hydrogen-tonded and monomeric water molecules. No evidence for molecular ions was observed. Strong evidence is found that strong intermolecular hydrogen bonds persist to $12 \mathrm{GPa}$, decreasing in importance above that pressure. At $26 \mathrm{GPa}$, water is essentially monomeric.

We are pleased to thank A. C. Mitchell for his valuable contributions throughout the course of this work, and to $B$. J. Mysen who kindly supplied us with his Gaussian decomposition code. We are grateful to C. D. Wozynski, R. C. Pederson, and R. B. Schuldheisz for operation of the two-stage light-gas gun, and to J. I. Miller for projectile fabrication.

\section{ACRNOWLEDGEMENTS}

Work performed under the auspices of the U.S. Department of Energy by the Lawrence Livermore National Laboratory under contract number W-7405-ENG-48.

\section{REFERENCES}

1. A. C. Mitchell and w. J. Nellis, Equation of State and Electrical Conductivity of Water and Ammonia Shocked to the $100 \mathrm{GPa}$ (1 Mbar) Pressure Range. J. Chem. Phys. 75:6273 (1982).

2. H. G. David and S. D. Hamann, The Chemical Effects of Pressure, Part 5. The Electrical Conductivity of Water at High Shock Pressures, Trans. Faraday Soc. 55:72 (1959).

3. S. D. Hanann and M. Linton. Electrical Conductivity of water in Shock Jompression, Trans. Faraday Soc. 62:2234 (1966).

4. S. D. Hamann and M. Linton, Electrical Conductivites of Aqueous Solutions of $\mathrm{KCl}, \mathrm{KOH}$, and $\mathrm{HCl}$, and the Ionization of Water at High Shock Pressures, Trans. Earaday Soc. 65:2186 (1969).

5. S. C. Schmidt, D. S. Moore, and J. W. Shaner, Raman Spectroscopies in Shock-Compressed Materials, in: "Shork Waves in Condensed Matter-1983," J. R. Asay, R. A. Graham, G. R. Straub, ed., Elsevier, Amsterdam (1984).

6. A. Delpuech and A. Menil, Raman Scattering Temperature Measurement Behind a shock Wave, ibld.

7. S. C. Schmidt, D. S. Moore, D. Schifer 1, and J. W. Shaner, Backward Stimulated Raman scattering in shock-Compressed Benzene, Phys. Rev. Lett. 50:661 (1983).

B. A. H. Jones, H. M. Isbell, and C. J. Maiden, Measurement of the Very-High-Pressure Properties of Materials using a Light-Gas Gun, J. Appl. Phys. 37:3493 (1966).

9. A. C. Mitche 11 and $W . J$. Nellis, Diagnostic System of the Lawrence Livermore National Laboratory Two-Stage Light-Gas Gun, Rev. Sci. Instr. $52: 347$ (1981).

10. A. C. Mitchell and W. J. Nellis, Shock Compression of Aluminum, Copper, and Tantalum, J. Appl. Phys. 52:3363 (1981). 
11. M. B. Rice and J. M. Walst, Equation of State of water to 250 Kilobars, J. Chem. Pinys. 26:824 (1957).

12. Ya. B. Zel'dovich and Yu. P. Raizer, in: "Physics of Shock Waves and gigh-Temperature Hyjrodynamic Phenomena", Plenum, New York (1967).

13. M. Cowperthwaite and $R$. Shaw, $C v(T)$ Equation of State for Liquids. Calculation of the shock Temperature of Carbon Tetrachloride, Nitromethane, and Water in the 100-kbar Region, J. Chem. Phys. $53: 555$ (1970).

14. C. W. F. T. Pistorius, M. C. Pistorius, J. P. Blakey, and L. J. Admiraal, Melting Curve of Ice VII to $200 \mathrm{kbar}, \mathrm{J}$. Chem. Phys. $38: 600$ (1963).

15. H. Lindner, doctoral dissertation, University of Karlsruhe, (1970).

16. J. R. Scherer, M. K. Go, and S. Rint, Raman Spectra and Structure of water from -100 to $90^{\circ}$, J. Phys. Chem. 78:1304 (1974).

17. G. E. Walrafen, Raman Spectral Studies of the Effects of Temperature on Water Structure, J. Chem. Phys. 47:114 (1967).

18. G. E. Walrafen, M. Abebe, F. A. Mauer, S. Rlock. G. J. Riermarini, and R. Munro, Raman and $X$-ray Investigations for Ice vII to 36.0 GRa, J. Chem. Phys. 77:2166 (1982).

19. B. J. Mysen, private comunication, (1985).

20. W. R. Busing and D. F. Hornig, The Effect of Dissolved RBr, ROH, or $\mathrm{HCl}$ on the Raman Spectrum of water, J. Chem. Phys. 65:284:1961).

21. i. Giguere and $C$. Madec, Spectroscopic Evidence for Ion-Pairs of Hydroniun Halides in Liquid Sulphur Dioxide, Chem. Phys. Lett. $37: 569$ (1976).

22. M. Eigen and L. De Maeyer, Self-Dissociation and Protonic Charge Transport in Water and Ice, Proc. Boyzl Soc. London Ser. A 247:505 (1958). 